\title{
Estado, Mercado e Comunidade: A economia portuguesa e a governação contemporânea
}

The State, the Market and the Community: The Portuguese economy and contemporary governance

État, marché et communauté: L'économie portugaise et la gouvernance contemporaine

José Reis

\section{(2) OpenEdition}

\section{Journals}

Edição electrónica

URL: http://journals.openedition.org/rccs/1050

DOI: $10.4000 /$ rccs. 1050

ISSN: 2182-7435

\section{Editora}

Centro de Estudos Sociais da Universidade de Coimbra

\section{Edição impressa}

Data de publição: 1 Dezembro 2004

Paginação: 81-100

ISSN: 0254-1106

\section{Refêrencia eletrónica}

José Reis, «Estado, Mercado e Comunidade: A economia portuguesa e a governação contemporânea », Revista Crítica de Ciências Sociais [Online], 70 | 2004, colocado online no dia 01 outubro 2012, criado a 30 abril 2019. URL : http://journals.openedition.org/rccs/1050; DOI : 10.4000/rccs.1050 


\title{
Estado, Mercado e Comunidade: A economia portuguesa e a governação contemporânea*
}

\begin{abstract}
A economia portuguesa registou muitas e significativas transformações nas décadas recentes, depois da revolução democrática de 1974 e da adesão à CEE em 1986. Uma integração profunda na UE e um original e inesperado contexto de integração ibérica são partes importantes do novo retrato. As mudanças na especialização produtiva, a emergência de uma economia terciária pública, a centralidade das relações financeiras externas e a nova condição de Portugal enquanto investidor líquido no estrangeiro e país de imigração são alguns dos processos principais para a análise da governação da economia portuguesa neste período. Este último propósito implica estudar os mecanismos de coordenação da acção colectiva. O Estado, enquanto agente da "ordem relacional", o mercado, enquanto lugar de governação cada vez mais estreito, e a comunidade, enquanto expressão das especificidades internas portuguesas, são considerados neste texto arranjos institucionais principais e bases da governação económica.
\end{abstract}

\section{Introdução: governação, contingência e complexidade}

Este texto tem dois objectivos principais. O primeiro é ensaiar um quadro de análise sobre a governação económica e, com isso, proceder a uma apresentação das características estruturais e das dinâmicas de uma economia nacional, a portuguesa. O segundo é sublinhar a intuição, de que parto, de que lidar com um caso singular em economia é lidar com originalidades, contingências, trajectórias inesperadas.

O primeiro propósito - o estudo da governação - é uma tarefa ampla, necessariamente atenta a muitas dimensões. ${ }^{1}$ Para a finalidade deste artigo, vou, contudo, olhar para a governação apenas através de uma tentativa de operacionalização analítica das acções do Estado e do mercado. Adicional-

\footnotetext{
* Uma versão em inglês deste artigo, com o título "State, Market and Community: The Portuguese Economy in the Networks of Contemporary Governance”, estará disponível como Oficina do CES em 2005.

${ }^{1}$ A governação assenta numa taxonomia dos arranjos institucionais que inclui vários modos de coordenação da acção colectiva: Mercados e Hierarquias Empresariais (que exprimem o auto-interesse, assentando os primeiros em formas de poder horizontal e as segundas numa forma de poder vertical); Comunidades e Estado (que exprimem normas sociais compulsórias, assentando as primeiras em formas de poder horizontal e o Estado em formas de poder vertical); Associações e Redes (em que se regista uma combinatória de formas de poder e de motivos para a acção). Cf. Hollingsworth e Boyer (1977).
} 
mente, trato da comunidade, mas apenas para sublinhar, circunstancialmente, que aí reside um elemento-chave dos desempenhos económicos e de alguns dos seus equilíbrios. Por comunidade entendo as estruturas materiais internas da sociedade e as culturas práticas dos actores sociais. Isto é, refiro-me, em concreto, às fontes de heterogeneidade estrutural da sociedade portuguesa. Trata-se de aspectos largamente relacionados com o facto de Portugal ser um exemplo de capitalismo intermédio, dificilmente estruturado em termos modernos e articulado com a economia mundial de um modo limitado e tardio.

Captar os mecanismos da governação para dar um sentido operativo às acções do Estado e do mercado é um ponto de vista que privilegia o estudo das dinâmicas relacionais. A fenomenologia económica - onde certamente se encontra o incerto, o imprevisto e o original - é, nesta perspectiva, um campo de análise mais rico do que as visões deterministas e funcionalistas. É neste contexto que ganha sentido a ideia de que os mecanismos que governam e coordenam as economias e as sociedades contemporâneas são vários e a sua acção é plural. De facto, as explicações monocausais raramente são satisfatórias. Acho, em especial, que a mais recente hegemonia das visões globalistas e a crítica que elas merecem acentuaram a necessidade de afinar um dispositivo de análise que dê muito mais atenção à complexidade das relações económicas. É isso que é apontado pelo que chamo a alternativa institucionalista ao funcionalismo globalista. Faz parte dessa alternativa a ideia de que a organização das economias continua a basear-se num tensão entre mobilidades e territorializaçôes. Contraria-se, assim, a exclusiva lógica de fluxos em que assenta o pressuposto globalista do privilégio da mobilidade, da deslocalização e do acesso rápido e instantâneo a tudo: mercados, factores de produção... De igual modo, entende-se também que a expressão da complexidade se encontra no papel das instituições ${ }^{2}$, que são a "espes-

\footnotetext{
${ }^{2}$ A tensão entre mobilidades e territorializações e as instituições são dois dos quatro pilares em que baseio uma alternativa institucionalista para a análise das dinâmicas e das formas de organização das economias contemporâneas (Reis, 2001). Outro pilar é o do reconhecimento dos limites da racionalidade e da organização. Sabemos que o pressuposto da mobilidade e os grandes "desenhos" do mundo têm sempre por trás a ideia de que há super-actores sociais, clarividentes e plenamente informados, que agem com grande intencionalidade e total racionalidade. Contudo, a hipótese da absoluta racionalidade e intencionalidade das acções humanas tem sido sempre confrontada com limites, restrições morais, dependências relacionais e capacidades apenas parciais de processamento de informação. Veja-se Herbert Simon (1986) e Kenneth Arrow (1974), como exemplo de economistas sofisticados que baseiam as suas obras em pressupostos deste tipo.

Por isso mesmo - este é mais um dos quatro pilares - a incerteza e a contingência são elementos dos processos inovatórios, com um lugar muito mais central do que o que lhes é dado pelos modelos racionalistas, visto que estes reconhecem apenas as práticas rotinizadas dominantes. É na medida em que se valorize este pilar que se recuperam as dimensões morais e humanas da vida. E é este pressuposto que nos permite entender que, nos processos de desenvolvimento e de inovação, as trajectórias inesperadas são coisa certa.
} 
sura" do território, contrariando o pressuposto da auto-suficiência da regulação mercantil. Por isto mesmo, o quadro preciso de funcionamento de uma economia apresenta-se frequentemente delimitado por relações institucionais complexas e por um jogo de forças e de dinâmicas de evolução que resultam, designadamente, da tensão, acima referida, entre mobilidades e territorializações.

\section{A economia portuguesa: trajectórias, originalidades, imprevistos}

Ao longo das décadas mais recentes, Portugal, enquanto economia, registou muitas mudanças e originalidades assinaláveis. Por exemplo: passou, subitamente, a assentar a sua integração europeia numa integração ibérica de proximidade; tornou-se num investidor líquido no estrangeiro; o investimento directo estrangeiro no país, que nunca foi elevado, deixou de ser significativo; as suas exportações industriais já não se baseiam especialmente no têxtil e vestuário; passou a atrair um número elevado de imigrantes; utiliza fortemente poupança externa para as novas estratégias de consumo das famílias; as relações financeiras tornaram-se centrais no seu envolvimento externo. Dir-se-ia que tudo isto (mesmo o imprevisto) é natural numa fase de globalização da economia e de uma grande centralidade do mercado.

A verdade, porém, é que são muitos os sinais de que uma explicação deste tipo é demasiado limitada e aponta frequentemente em sentidos opostos. Dou três exemplos. Primeiro, é natural esperar-se que o papel do mercado e a influência da globalização conduzam ao alargamento das relações de troca, numa escala espacial sempre mais ampla. Contudo, acontece que o espaço geográfico em que a economia portuguesa assenta as suas trocas é cada vez menor. Segundo, se consideramos a terciarização das economias um processo determinado pela preponderância crescente dos serviços económicos e do mercado, sucede que, diferentemente, a predominância terciária da economia portuguesa resulta de um papel central do Estado e dos serviços que ele fornece. Terceiro, se acharmos que a integração europeia acelera a circulação de capitais produtivos numa pequena economia, verifica-se, pelo contrário, que a economia portuguesa está a receber pouco investimento, ao mesmo tempo que tende a assumir o papel de investidor em países não-europeus.

Como é que damos sentido a estes processos? Um pequeno exercício teórico retrospectivo permite situar melhor as minhas proposições. Portugal é uma economia europeia de desenvolvimento intermédio. Esta velha hipótese de trabalho, que se filiava na visão da economia-mundo de Immanuel Wallerstein (1974), pressupunha que a sociedade portuguesa conjuga características do centro e da periferia (o que lhe dá o seu carácter intermédio) e, adicionalmente, desempenha funções de intermediação no interior 
do próprio sistema-mundo. Tal hipótese, que levou a qualificar a economia portuguesa como semiperiférica, originou um amplo programa de pesquisa. ${ }^{3}$ Esse programa conteve sempre elementos críticos assinaláveis, os quais convocavam tensões criativas com a visão original. Saliento uma dessas críticas. Duvidava-se que, para captar as especificidades da economia portuguesa, a função de intermediação fosse relevante ou, pelo menos, tão relevante como as suas características estruturais intermédias. Por isso, defendia-se que a determinação das suas dinâmicas pela sua inserção estrutural, isto é pelo seu papel funcional dentro do sistema mundial, devia ser severamente sujeita a um confronto com outras hipóteses, designadamente a de que a proximidade e as territorialidades são particularmente significativas nas trajectórias seguidas pela economia. É a presença de relações institucionais complexas, de oportunidades desencadeadas pela proximidade física ou cultural, de articulações entre modos plurais de governação económica que nos ajuda a reconstruir o sentido destes processos. Tais relações formam redes - bem mais amplas do que as que resultam das relações mercantis - que mobilizam especificidades e capacidades inesperadas da sociedade. E isso dá lugar a uma diversidade de modos de governação, tornando-se, assim, compreensível que a determinação estrutural não é o único factor explicativo com que temos de lidar.

Recuemos um pouco na história económica. No início do século XIX, por volta de 1830, a economia portuguesa registava um nível de criação de riqueza por habitante (medido pelo produto per capita) comparável aos de outros dez países europeus desenvolvidos, fossem eles de grande ou de pequena dimensão. ${ }^{4}$ Portugal detivera uma posição importante no capitalismo comercial em que se baseou a economia-mundo subsequente ao século XV. Contudo, o processo de crescimento moderno, representado sobretudo pela disseminação da revolução industrial, fez entrar a economia portuguesa numa trajectória de empobrecimento relativo, em que a dominação informal da Inglaterra, uma pauta alfandegária liberal e a ausência dos recursos necessários à chamada primeira industrialização ocuparam lugar de relevo.

É certo que os anos 20 e 30 do século XX trouxeram os primeiros vislumbres de industrialização, com crescimento económico assinalável, em termos relativos, e o lançamento de uma política de substituição de importações. Eram os primeiros passos de uma nova indústria, já ligada à expor-

\footnotetext{
3 Tomo como exemplo o programa de investigação desenvolvido pelo Centro de Estudos Sociais. As principais conclusões estão publicadas em Santos, 1993. Dei o meu contributo em Reis, 1993.

${ }^{4}$ Sigo a análise e os dados de Gonçalves (1998).
} 
tação. No pós-guerra, um processo industrialista relativamente intenso, baseado na hidroelectricidade e nas indústrias de base (química, siderurgia, cimentos), desenvolveu o mercado interno e consolidou uma matriz industrial com inter-relações produtivas modernizantes, alheias à ideia clássica e errada de que Portugal tem sido sempre um simples país agrícola. Contudo, os resultados alcançados acentuaram a natureza autárcica, administrativa e não concorrencial da trajectória económica, fechando a economia portuguesa num quadro em que a ausência de modernização social e política era gritante (Reis, 2003:33-35).

Estes acontecimentos têm lugar durante o período em que uma ditadura retrógrada, colonial e isolacionista submeteu o país (1926-1974). É este o tempo em que outras economias europeias haveriam de entrar no círculo virtuoso fordista, isto é, na modernização intensiva e no crescimento sustentado dos "trinta anos gloriosos" entre o pós-guerra e a crise do petróleo de 1973. Em Portugal, foi um período em que "nação e império [eram] categorias fundamentais na estratégia política e económica" (Murteira, 1997: 93). Entretanto, acontecimentos como a participação na criação da Associação Europeia de Comércio Livre, EFTA (Convenção de Estocolmo, em 1960) e o acordo com a Comunidade Económica Europeia, CEE, de 1972, foram relevantes. Mas só excepcionalmente a economia deixa de funcionar num ambiente protegido, condicionado e administrativamente regulado. ${ }^{5}$ Trata-se de um contexto em que é sempre saliente a intervenção do Estado e em que as iniciativas para gerar um adensamento da capacidade de organização interna da indústria foram sempre frustradas. As indústrias mecânicas e eléctricas consolidaram-se ao lado dos sectores do têxtil, do vestuário e do calçado, que representavam o "excesso de especialização" da nossa estrutura produtiva, mas o seu desenvolvimento foi débil. A abertura ao envolvimento externo, enquanto "tendência de longo prazo dominante na trajectória portuguesa" (Murteira, 1997: 94) não se fez, pois, sem grandes dificuldades. Essa abertura, possibilitada pelo aprofundamento da integração no espaço europeu, foi "relutante" e esteve marcada por fortes particularidades. Afinal, estávamos em presença de uma economia "duradouramente periférica", sujeita a uma "regulação condicionada", cujo traço mais saliente foi um crescimento sem qualificação do conjunto da sociedade.

Por isso, um factor-chave da compreensão das incapacidades de endogeneização do crescimento industrial dos anos 50 e 60 é a emigração, que foi a forma mais intensa de inserção internacional da economia portuguesa.

\footnotetext{
5 A excepção mais notória, porventura a única, é o desenvolvimento de um sector de construção e reparação naval, em 1961, dirigido ao mercado internacional. A crise do petróleo haveria de fazer deste processo um acontecimento transitório.
} 
De facto, nas décadas de maior abertura da economia, "a principal exportação para os mercados europeus foi uma mercadoria muito particular, a mão-de-obra" (Reis, 2003: 41) - uma integração "por via da 'economia do trabalho'”, como sublinha Mário Murteira (1997: 96), que assinala devidamente o facto de o "económico" e o "humano" terem em Portugal um alinhamento inverso do que se registou noutras economias semelhantes, visto que, no caminho português, o desenvolvimento dos recursos humanos vai atrás do crescimento. Vários aspectos estarão com isso relacionados. Por exemplo, o facto de só a partir da adesão à CEE as exportações portuguesas aumentarem mais do que as exportações mundiais, pois até aí, e apesar da abertura da economia, Portugal não beneficiou da expansão do comércio internacional. Só a partir de meados da década de oitenta é que as exportações portuguesas alcançaram um patamar, de que ainda hoje não saíram, correspondente a cerca $20 \%$ do PIB.

É também relevante a circunstância de, ao lado da emigração, do desenvolvimento de uma matriz de indústrias básicas e de uma tendência para a extroversão, a formação social portuguesa ter sempre um "recurso à mão", usado como bem "livre": a plasticidade das suas estruturas internas. Refiro-me, por exemplo, ao meio rural e às pequenas estruturas urbanas, de carácter não-metropolitano, aos territórios onde se combinavam actividades de diferente natureza, espécie de reserva do desenvolvimento, ao sector informal e às estratégias familiares flexíveis. Foi assim que se geraram dinâmicas ou efeitos de compensação de vária ordem. Alguns têm características "defensivas", como as relações entre uma agricultura de natureza complementar e informal e mercados de trabalho dinamizados pela indústria ou pelos serviços de pequena e média dimensão e baixos salários. Outros são mais "activos", como acontece quando a multidimensionalidade das economias familiares gera formas de reprodução social mais avançadas do que os indicadores formais deixariam supor. Outros ainda são portadores de capacidade inovadora, como os sistemas produtivos locais onde se adensam capacidades produtivas relevantes para o conjunto da economia (em várias especializações locais conhecidas). ${ }^{6}$

Em resumo, estamos, portanto, perante uma economia que gerou autarcicamente uma industrialização periférica, que se inseriu nos mercados internacionais de mercadorias de forma difícil (visto que a exportação de mão-de-obra representou uma inserção mais intensa do que a de produtos), que convocou repetidamente as especificidades internas para calibrar a sua organização e atingir alguns equilíbrios. É esta mesma economia que hoje conhece novos processos de mudança.

\footnotetext{
${ }^{6}$ Para uma análise centrada em perspectivas territorialistas cf. Reis e Négrier (1998) e Reis (2000).
} 


\section{Estado, mercado e comunidade: a coordenação da economia}

Portugal é uma economia periférica na Europa, o que a distingue radicalmente da perificidade absoluta que ocorre no quadro do sistema mundial. Olhemos, contudo, para a sua estrutura interna. O mercado, o Estado e as hierarquias empresariais não têm a mesma robustez e capacidade de auto-sustentação - a mesma força e a mesma autonomia - que encontramos nos sistemas de governação predominantes na Europa. Pelo contrário, dependem mais fortemente uns dos outros e registam, cada um, debilidades assinaláveis. A dependência do Estado perante grupos de interesse é forte. Contudo, é o próprio Estado que desenha os aspectos principais das relações económicas, visto que a capacidade empresarial e da sociedade civil para desencadearem iniciativas activas, independentes e suficientemente estruturadas é fraca. Um Estado fraco é, pois, um actor público central perante agentes civis ainda mais fracos. O papel estatal é crucial no estabelecimento de consensos e de opções, na definição de regras de concorrência, na integração em regimes internacionais ou no que diz respeito aos custos da força de trabalho e do bem-estar da população. Da mesma forma, as condições infra-estruturais da economia e da sociedade, devidas em muito às contribuições dos fundos estruturais da União Europeia, tornaram-se elementos-chave do desempenho económico e são poderosos elementos de geração de economias externas, designadamente em sectores como os da engenharia.

A comunidade, por seu lado, sendo também fraca quando se trata de se exprimir autonomamente, é forte em situações defensivas, isto é, quando se apresenta como factor de compensação das debilidades de outros mecanismos de coordenação da vida colectiva ou quando se trata de desenvolver iniciativas intersticiais, associadas à vida local, à iniciativa de pequena dimensão, às relações salariais ou até a formas de inovação social. Em sociedades deste tipo, a urbanização é mais difusa, os contextos de ruralidade transformam-se através mecanismos diferentes dos que marcaram a modernização agrícola na Europa - em que prevaleceu a chamada "industrialização" da agricultura -, as estruturas produtivas industriais baseiam-se em modelos de especialização e de qualificação que, na ausência de transformações espectaculares, revelam gaps muito fortes relativamente aos outros sistemas, sendo também notória a sua dependência face a processos e sectores ditos "tradicionais".

O exercício que se segue parte do pressuposto de que a economia é formada por um conjunto de dispositivos institucionais que agem como meca-

\footnotetext{
${ }^{7}$ Por exemplo, a indústria portuguesa que, nas últimas duas décadas, mais reduziu as diferenças de produtividade foi a que é classificada como de baixa intensidade tecnológica.
} 
nismos de coordenação dos actores económicos e sociais. Pretendo, através desta análise, captar as formas, os processos materiais que melhor representam e caracterizam cada um deles. No mesmo passo, procuro mostrar os limites da governação mercantil e a interligação estreita entre os vários mecanismos de coordenação da economia e da sociedade.

\subsection{O mercado: um lugar de governação cada vez mais estreito?}

O que é o mercado? Esta é, porventura, a pergunta menos respondida pela teoria económica. Não tratando agora das dimensões teóricas do problema, uma questão elementar e muito prática é a de saber como podem representar-se, de um ponto de vista empírico, as relações mercantis que caracterizam globalmente uma economia nacional. Consideremos os planos interno e externo. As relações mercantis externas indicam a dimensão e as características dos mercados internacionais e podem observar-se nas trocas comerciais externas, nas relações financeiras (incluindo aí o investimento nacional no estrangeiro e o que o país recebe proveniente do exterior) e na mobilidade das pessoas (procurando serviços, como o turismo, ou procurando trabalho). As relações mercantis internas podem representar-se na organização da produção e do emprego, na especialização internacional, na estrutura empresarial e no mercado do trabalho.

Numa análise deste tipo, não tardará a verificar-se que muitos dos aspectos que compõem esta realidade empírica não se limitam a exprimir relações mercantis. Certamente que aí encontraremos também o Estado e a comunidade. Quer dizer, a regulação mercantil não existe separada da regulação institucional nem das relações societais, sejam elas formais ou informais. Ao mesmo tempo, tão difícil como responder à pergunta sobre o que é o mercado é definir materialmente o Estado. Se não se tratar apenas de delimitar o aparelho estatal ou, por exemplo, avaliar o peso da despesa pública na economia, e se, mais ambiciosamente, quisermos definir a regulação pública e institucional, então é muito largo o conjunto de questões que se abre, apontando para a ordem relacional e para a contratualidade política e social. Qual é, por exemplo, a forma de conceber a integração europeia? Sabe-se que ela resulta de uma decisão pública e política e desencadeia a criação de novas regras e novas normas. É um assunto da acção estatal e não um simples processo de integração ou alargamento de mercados.

Neste sentido, procuro agora mostrar ${ }^{8}$ que o mercado internacional em que a economia portuguesa se envolve é geograficamente estreito, que a

\footnotetext{
${ }^{8}$ Salvo indicação em contrário, a informação quantitativa que uso nesta seccção 3.1. resulta dos dados disponibilizados pelo Banco de Portugal no seu site.
} 
transformação da especialização produtiva é o resultado de relações internacionais limitadas, que a emergência de uma economia terciária deve mais ao Estado do que às dinâmicas do mercado, que a produção interna é insuficiente para financiar a economia nacional e que a presença mais impressiva nas relações internacionais é o resultado de processos inesperados. ${ }^{9}$

\section{As trocas com o exterior: o 'fechamento' europeu e ibérico da economia portuguesa}

Nas décadas recentes, a característica mais marcante da articulação da economia portuguesa com os mercados internacionais de bens e serviços foi o estreitamento da sua geografia relacional. Duas imagens claras exemplificam do que se trata: em 1970, a estrutura do comércio externo de Portugal mostrava que os 15 países que constituíam a União Europeia no início de 2004 eram destino para apenas $52 \%$ das mercadorias exportadas por Portugal (65\% em 1980). Hoje, eles representam cerca de $80 \%$, sendo este valor praticamente estável desde a adesão, em 1986. A Espanha, que recebia $1.6 \%$ das exportações portuguesas em $1970,3.6 \%$ em 1980 e $10.8 \%$ no período 1986-1990, foi em 2003 o destino de $22.7 \%$ das mercadorias portuguesas enviadas para o exterior. Em suma, encarada a partir das trocas internacionais de mercadorias, a posição de Portugal na economia mundial é sobretudo um lugar na Europa e a posição de Portugal na Europa é sobretudo um lugar na economia ibérica.

Estes dados não são apenas aritmética do comércio externo português. Para além de evidenciarem uma geografia limitada, eles revelam que esse comércio resulta de uma forte realidade institucional, mais do que económica. É o quadro institucional da integração europeia que estrutura e determina em grande parte o relacionamento externo da economia portuguesa. A importância crescente das relações infra-europeias baseadas na proximidade - criando uma espécie de integração sub-regional dentro da Europa é também clara. Adicionalmente, revela-se a condição específica da vizinhança entre dois países que nunca tinham sido parceiros económicos de relevo e que reinventaram a proximidade num contexto de integração num espaço institucional e político mais largo. Ou seja, a ideia abstracta de mercado (espaço geonómico, livre, universal e aterritorial) é aqui confrontada com os mecanismos das relações territoriais, das redes, das diminuição dos custos de transacção, da governação institucional.

A economia portuguesa é, pois, crescentemente a economia de um espaço intra-europeu e a de um dos sistemas da macro-regulação europeia, neste

\footnotetext{
9 Em Reis (2002) analisei as novas dinâmicas da economia portuguesa, dando particular atenção à sua "iberização" e ao papel dos movimentos de capitais.
} 
caso o ibérico. ${ }^{10}$ Nos dias de hoje predomina um discurso sobre a globalização em que o mundo é visto como se fosse apenas a economia e a economia é vista como se fosse o mundo. Ora, tem de nos causar alguma perplexidade que a geografia de uma economia aberta europeia seja um pequeno espaço do mundo, e se trate de um espaço protegido e institucionalmente construído.

\section{A especialização internacional: o fim da mono-especialização}

Estas mudanças da geografia do comércio externo foram acompanhadas de mudanças na estrutura produtiva interna. $\mathrm{Na}$ indústria, considerando a criação de riqueza, predomina hoje a produção de bens da fileira "metálica e electrónica" (máquinas e equipamentos metálicos, material de transporte e componentes metálicas, eléctricas e electrónicas). O "têxtil, vestuário e calçado" já não é o sector que representava uma espécie de mono-especialização internacional da economia portuguesa. De facto, a fileira metálica representa hoje $23.4 \%$ do valor acrescentado industrial, enquanto a fileira têxtil constitui $20.9 \%{ }^{11}$ Nas exportações, os valores respectivos são $35.5 \%$ e $23.6 \%$.

Esta bi-especialização distingue a economia portuguesa de outras com que é possível compará-la. Por exemplo, a economia espanhola acentuou a sua especialização na fileira metálica e electrónica $(41.2 \%$ das suas exportações vs. 35.9\% em Portugal) e é muito menos dependente da fileira têxtil, vestuário e calçado $(6.6 \%$ vs. $23.6 \%)$. Por outro lado, as exportações de Espanha assentam mais do que as portuguesas em produtos alimentares ( $11.9 \%$ vs. 4.2) e nos produtos químicos ( $10.4 \%$ vs. $5.7 \%)$, o que nos dá ideia de que a economia espanhola tem uma estrutura de relacionamento com o mercado internacional mais densa e sofisticada que a portuguesa. É na comparação com a Grécia que a estrutura das exportações portuguesas se revela mais favorável, pois aquela é menos robusta na fileira metálica e electrónica, assemelha-se à portuguesa no têxtil, vestuário e calçado e não revela mais nenhum sector de especial significado. Outro tanto não se passa com a Irlanda (um país periférico e em rápida transformação estrutural), pois neste caso a indústria química e as máquinas e o material de transporte representam só por si $74.3 \%$ das exportações deste país, tendo perdido significado os sectores considerados tradicionais.

A mudança ocorrida em Portugal nestes domínios deveu-se ao papel exercido pelo investimento estrangeiro. Sucede, porém, que estamos perante

\footnotetext{
${ }_{10}$ Dediquei-me a uma apreciação da governação territorial na Europa em Reis (2004).

${ }^{11}$ No emprego, a fileira têxtil representa $33.3 \%$ e a fileira metálica $20.9 \%$, o que indica a grande diferença de produtividade entre ambas (a produtividade da segunda é 1.8 vezes a da primeira).
} 
uma pequena fracção de capital, de volume limitado, e agindo apenas num segmento da indústria nacional, embora num segmento importante. Os efeitos que produziu na especialização produtiva e na estrutura das exportações foi, contudo, muito significativo. As diferenças internacionais de salários e a presença de subcontratados potenciais de fácil acesso nos sectores tradicionais foram, certamente, factores explicativos importantes do que aconteceu. Tratou-se, pois, do aproveitamento de uma oportunidade oferecida por condições internacionais desiguais no plano salarial. Foi, contudo, uma oportunidade insuficiente para qualificar significativamente a estrutura industrial, pelo menos em termos comparáveis aos da Espanha e da Irlanda.

\section{A emergência de uma economia terciária: uma economia de serviços pública}

A emergência de uma economia de serviços é geralmente considerada um sinal de novos desempenhos económicos. O crescimento terciário dinamiza os mercados em novas áreas (serviços às empresas, desenho organizacional, processos de inovação). Ele é também um indicador da presença de processos não-materiais e intelectuais que alteram a composição do valor criado.

A economia portuguesa há muito que deixou de ser uma economia agrícola, já se disse. De 2000 para cá, a agricultura origina menos de 4\% da riqueza produzida, embora ainda represente quase $10 \%$ do emprego. Estamos, portanto, perante uma economia terciarizada, pois a própria indústria transformadora representa hoje em dia apenas $18 \%$ do produto e $19 \%$ do emprego. Trata-se, como se sabe, de traços comuns à generalidade das economias que se industrializaram e amadureceram as suas estruturas produtivas, os mercados de trabalho, as formas de consumo e de reprodução social.

Uma perspectiva comparada é, também aqui, bastante esclarecedora. A economia portuguesa compara-se com a da UE-15 do seguinte modo (considerando a estrutura da criação de riqueza, isto é, o produto): esta última é mais terciária $(70.1 \%$ vs. $66.9 \%)$, um pouco mais industrial $(19.3 \%$ vs. $18.2 \%$ ) e menos agrícola ( $2.3 \%$ vs. $3.9 \%)$. As maiores disparidades absolutas registam-se no sector da construção (5.4\% vs. $7.8 \%$ ) e, especialmente, dentro do sector dos serviços. De facto, se decompusermos este sector em serviços não-mercantis (maioritariamente representados pelos serviços prestados pelas administrações públicas) e em serviços económicos, verifica-se que um nível global quase idêntico de terciarização da economia tem, contudo, um significado diferente para os dois subconjuntos: em Portugal a economia de serviços tem uma forte influência do desenvolvimento de serviços colectivos de natureza pública ou social (a relação UE-15/Portugal é $21.7 \%$ vs. $27.2 \%$ ), enquanto na União Europeia o sector dos serviços é muito mais estruturado à volta do sub-sector dos serviços económicos 
(a relação UE-15/Portugal é 48.4\% vs. 39.7\%). De facto, o próprio crescimento dos serviços em Portugal desde o início da década de oitenta $(23 \%$ contra $17 \%$ na UE-15) regista sobretudo o efeito dos serviços colectivos (que crescem 36\% em Portugal e 5\% na UE-15), enquanto os serviços económicos só crescem $15 \%$ no nosso país (24\% na UE-15).

Este é um ponto onde se regista uma grande sobreposição entre Estado e mercado. Isto é, se considerarmos a terciarização das economias como um processo que ilustra bem as dinâmicas contemporâneas do mercado (pela inovação, diferenciação e qualificação que implica), então estamos perante um espaço de governação mercantil débil. O lugar deixado pelo mercado é preenchido pela terciarização pública, através dos serviços sociais não-transaccionáveis ${ }^{12}$. O Estado tende, pois, a ficar sozinho nas dinâmicas de terciarização. Não substitui o mercado, dado que não faz o que ele deixa de fazer, mas ganha a importância percentual que aquele deixa "livre".

\section{As relações com o exterior e o investimento directo: novas e velhas questões}

Em termos quantitativos, a economia portuguesa nunca recebeu montantes muito elevados de investimento directo por parte de empresas estrangeiras. Isso não significa, evidentemente, que não fossem significativos os efeitos modernizadores desse tipo de investimento. A seguir a 1986, data da adesão às comunidades europeias, registaram-se, como já vimos, fortes entradas de capitais, por esta via, na economia portuguesa. No período 1988-1992, o investimento directo exterior em Portugal terá sido, em média, da ordem dos $3 \%$ do PIB. Tratou-se, essencialmente, da entrada de capitais estrangeiros em sectores de exportação, designadamente no sector automóvel e electrónico, não sendo, portanto, alheio às alterações já referidas na especialização industrial e na estrutura das exportações. Contudo, a partir de meados da década de noventa o investimento directo passou a ter pouca importância nas necessidades de financiamento da economia, apesar de o stock mundial de investimentos no exterior ter crescido a uma média anual de cerca de $15 \%$ e de vários países europeus se destacarem entre os principais importadores de capital. Portugal representa apenas $0.5 \%$ do total captado pela Europa, sendo o IDE apenas $6 \%$ do investimento total realizado no país, quando esta relação é 18\% na UE, 11\% em Espanha e 48\% na Irlanda (DPP, 2003).

Ao mesmo tempo que isto acontecia, registou-se um fenómeno absolutamente novo: a economia portuguesa tornava-se investidora líquida no estran-

\footnotetext{
12 Bens não-transaccionáveis são aqueles que não estão sujeitos à concorrência externa: são fundamentalmente serviços ou, por exemplo, transportes. Isto é, aqueles bens que, dada a natureza específica da sua oferta e do seu consumo, têm o seu mercado territorialmente delimitado.
} 
geiro. Isso aconteceu de 1998 até 2002. O Brasil foi o principal mercado de destino do investimento português, pois captou 39\% do investimento português no exterior no período 1996-2001. Na União Europeia, não é de estranhar, pelo que já se disse, que Espanha tenha sido o principal destino (22\%). É significativo que o sector dos serviços e, dentro dele, as actividades imobiliárias e os serviços às empresas, os bancos e as empresas de distribuição se destaquem tanto no investimento estrangeiro recebido como no que o país realiza no exterior (idem).

\section{As relações de financiamento da economia: o défice perante o exterior}

Portugal é uma economia constantemente deficitária. Importa mais mercadorias do que exporta (em 2001-2003, o saldo negativo foi de cerca de $10 \%$ do PIB). Gera excedente na prestação de serviços (através do turismo), mas esta vantagem (cerca de 3\% do PIB) fica longe de compensar a desvantagem anterior. Quer dizer, o turismo é uma função significativa da inserção de Portugal na economia internacional e nas mobilidades que a caracterizam (neste caso, a mobilidade de pessoas na procura de serviços), mas o seu efeito económico é limitado. Limitado é também o efeito das remessas dos emigrantes (que tendem a situar-se entre $2 \%$ e $3 \%$ do produto, depois de terem atingido $12.6 \%$ em 1979). A balança de capital, onde se incluem as transferências da União Europeia sob a forma de fundos estruturais (e cujo saldo, em velocidade-cruzeiro, se situa em níveis idênticos ao das remessas dos emigrantes), é habitualmente excedentária. Contudo, é um dado estrutural que a economia portuguesa necessita de obter financiamento no exterior, isto é, necessita de usar poupança exterior, expressa em movimentos financeiros. $\mathrm{O}$ saldo dos movimentos de investimento do estrangeiro e no estrangeiro, os saldos do investimento de carteira e as operações de financiamento bancário constituem o essencial das relações financeiras (registadas na balança financeira) com que a economia portuguesa supre as necessidades resultantes das balanças correntes e de capital. Em 2001-2003, a economia portuguesa usou poupança externa em níveis que equivalem a quase $6 \%$ do PIB. $\mathrm{O}$ investimento directo tem sido, neste período, um meio de saída de poupança, pois, como já vimos, a economia portuguesa tornou-se investidora líquida no estrangeiro. Mas o traço essencial do funcionamento da economia portuguesa contemporânea está neste consumo recorrente da poupança dos outros.

A entrada de poupança exterior na economia portuguesa é assegurada principalmente através do bancos comerciais, que se financiam junto de entidades exteriores, procurando meios para prosseguir a suas políticas de 
concessão de crédito. Estas têm sido, aliás, extraordinariamente activas, num contexto em que os padrões de consumo das famílias portuguesas se alteraram muito, passando a incluir explicitamente estratégias de endividamento (o endividamento dos particulares representava, em 2002, $103 \%$ do seu rendimento disponível).

O equilíbrio entre criação de riqueza e dispêndio de riqueza não é, portanto, garantido internamente. O mercado enquanto lugar de produção é fraco. Ele é, contudo, activo enquanto lugar consumo. O equilíbrio só se restabelece através do recurso a poupança externa e usando as margens de manobra oferecidas pelo modo com as famílias organizam a gestão do seu endividamento.

\section{O mercado do trabalho e a mobilidade internacional de trabalhadores: a imigração como fenómeno original}

Portugal não é uma economia com uso escasso de mão-de-obra. Os seus cerca de 10.4 milhões de habitantes têm uma participação elevada no mercado de trabalho (51.8\%, em 2003, no total). Isto acontece tanto para os homens como para as mulheres. Na faixa dos 15 aos 64 anos, $78.5 \%$ dos homens são activos no mercado de trabalho. O mesmo acontece para $65.7 \%$ das mulheres: uma das taxas mais elevadas na Europa. A taxa de desemprego era, em 2003 , cerca de $6.4 \%$, mas o seu valor em anos anteriores situava-se na proximidade dos $4 \%$. Contudo a eficiência do uso desta mão-de-obra não é elevada.

A grande novidade do mercado de trabalho nacional é a intensa imigração registada nos últimos anos. Contabiliza-se em quase 500 mil o número de imigrantes, vindos de África, do Brasil e do Leste europeu que hoje estão em Portugal. Devido à sua expressão quantitativa e a um conjunto de características originais (proveniência, dispersão no território, qualificação e traços culturais) esta é uma das mais impressivas marcas sociológicas do nosso país na passagem de século (só comparável, porventura, à vaga de retorno de nacionais na sequência da descolonização).

\subsection{O Estado e as instituições: contratualidade e externalidades}

A economia não é só as estruturas materiais e relacionais dos mercados, da produção e do consumo. As instituições, as culturas de decisão, os comportamentos, a governação e as atitudes relacionais dos actores económicos e sociais são também economia. É necessário um paradigma económico mais amplo do que o que assenta na racionalidade do mercado para observar o modo como se estabelece a coordenação dos actores económicos, como se constrói a espessura do mercado, do Estado, da comunidade. 
$\mathrm{Na}$ análise que se segue, procura-se demonstrar em que consiste, no essencial, o papel do Estado enquanto agente de coordenação da vida colectiva interveniente na economia portuguesa. Vai insistir-se num visão relacional e numa óptica de contratualidade. Procura-se demonstrar que o Estado "calibra" as debilidades do mercado e também lhe consagra o âmbito de actuação em que este é capaz de agir: por exemplo, vamos encontrar o Estado enquanto agente de delimitação da capacidade relacional do mercado, em termos geográficos, ao estabelecer um regime internacional assente na União Europeia.

\section{O papel do Estado: a ordem relacional e as externalidades da economia}

A centralidade do Estado na economia portuguesa é grande porque é grande o seu papel na estruturação dos comportamentos dos actores sociais e das relações que estes estabelecem. De facto, os intervenientes no processo económico colocam-se numa grande dependência dos papéis que o Estado assume para estabelecer contextos de acção, fixar significados, estabelecer consensos (Reis, 2001b).

Há, assim, um contratualidade implícita nas relações entre o Estado e a economia. A este tipo de contratualidade chamo ordem relacional. A demonstração deste papel do Estado não se encontra nas estatísticas nem resulta de uma dedução aritmética. Está directamente ligada a uma interpretação das dinâmica relacionais. Ora, se considerarmos a construção da ordem económica saída da democratização (na década posterior a 1974), o que encontramos é, numa primeira fase, um forte papel estabilizador exercido pelo Estado, em vista da necessidade de criar um estrutura de direitos sociais até à época inexistente (direitos sindicais, laborais, salariais, direitos reguladores da segurança social, da saúde) e de qualificar as gerações futuras (com papel preponderante para a educação e para a formação profissional). Ainda nesta fase, a própria estabilização das variáveis macro-económicas é essencialmente um papel solitário do Estado, pois a regulação das relações monetárias externas, a condução da capacidade de troca, o desenvolvimento do crédito, o enquadramento da produção e do consumo, e até a salvaguarda da capacidade produtiva, tiveram lugar na ausência de parceiros sociais fortes e, sobretudo, autónomos e construtivos.

O quadro relacional da economia portuguesa na sua fase democrática teve, assim, o Estado no seu centro. Assim com o teve na fase da ditadura, com funções radicalmente diferentes. E o mesmo haveria de acontecer na fase que tem como epicentro a adesão à CEE (1986), em que o ambiente relacional da economia se estabilizou em novos termos. Tornaram-se então significativas as dinâmicas de urbanização, o planeamento, o financiamento 
das infra-estruturas básicas, o desenvolvimento dos transportes, dos serviços públicos sociais, o desenvolvimento da engenharia, entre muitos outros aspectos.

O Estado é, assim, um criador de externalidades. ${ }^{13} \mathrm{~A}$ produção de capital fixo social, de infra-estruturas modernizadoras, de qualificação geral da sociedade é um grande domínio de concretização material da função estatal. É compreensível que seja assim num país que, na década de setenta, entrava num processo de democratização, não apenas política mas também social. Tanto os direitos sociais e a qualificação humana quanto a modernização infra-estrutural exigiam esse capital fixo. No primeiro domínio estavam as infra-estruturas de educação, saúde, formação profissional. No segundo estavam as estruturas de mobilidade, bem-estar urbano, bem-estar individual, assim como os contextos materiais de funcionamento das empresas. Pode imaginar-se como este papel do Estado foi impressionante.

\section{A externalidade europeia: uma opção quasi-constitucional}

Este papel do Estado haveria ainda de ser particularmente significativo quando foi tomada uma opção estrutural e quasi-constitucional para a ordem económica: a integração europeia. O Estado criador de externalidades tem, de facto, a sua actuação decisiva na criação do que aqui vou chamar a externalidade europeia, a qual foi um assunto eminentemente político e institucional. Nesta matéria, como noutras, Estado e a política avançaram antes da sociedade.

O que estou a designar deste modo ("externalidade europeia") plasma-se num universo muito amplo de estruturas relacionais: no modelo social e político de referência, na lógica de regulação económica predominante (concorrência, modelo científico e tecnológico...), nas relações de mobilidade e, sobretudo, num contexto modernizador como aquele que a fase Delors instituiu na Comissão Europeia. A integração é, portanto, muito mais do que um processo de transferências monetárias, no âmbito da coesão social europeia. Para além dos aspectos político-institucionais e sociais, já vimos como, por exemplo, o contexto do comércio externo se redefiniu significativamente com a integração europeia. Mas é inquestionável que o processo de modernização infra-estrutural desencadeado pela integração dá ao Estado um papel material reforçado. Só a partir de 1992 (isto é, quando o II Quadro Comunitário de Apoio entra em velocidade-cruzeiro), é que o saldo das relações financeiras com a União Europeia atinge valores da ordem dos

\footnotetext{
${ }^{13}$ Uma externalidade positiva, em economia, é uma criação de benefícios para o conjunto dos agentes.
} 
$3 \%$ do PIB, valor idêntico ao que as remessas dos emigrantes assumem depois de 1995. Trata-se de um volume financeiro relevante, mas trata-se, sobretudo, de um factor criador de uma grande centralidade da esfera pública e, portanto, do Estado, nas suas diferentes dimensões. O Estado é, neste ambiente, o gestor da estratégia e dos seus recursos e significados, o "Senhor do Tempo", para retomar o título de um livro de há anos (Delmas, 1993).

Num contexto mais amplo, a "opção pela integração", que constitui a trave-mestra da definição do contexto de funcionamento da economia portuguesa, é, afinal, uma ilustração muito clara daquele que é o principal papel dos Estados nas economias contemporâneas - a definição dos regimes de relacionamento internacional para a acção dos actores económicos e das capacidades produtivas nacionais. De facto, basta que admitamos que a questão do papel do Estado não fica resolvida pelos postulados simplistas das visões liberais, para que esta questão desde logo se nos afigure como muito relevante. Ora, em Portugal, questões próprias das políticas europeias, como as grandes infra-estruturas de transporte e mobilidade, o sistema científico e tecnológico, a política da concorrência - que são questões de economia pública - são exemplos cabais da centralidade do próprio Estado, como resultaria de uma avaliação empírica do que se passa em cada um destes domínios. A imagem seria ainda mais clara se se juntasse a isto tudo o papel das políticas de coesão económica e social, isto é, do desenvolvimento regional e urbano e das infra-estruturas de bem-estar pessoal.

\section{A presença directa do Estado: modernização, terciarização da economia e despesa pública}

A noção de que o Estado é um parceiro central da contratualidade que configura a economia, o agente da ordem relacional, não deve fazer esquecer que o Estado de hoje tem também uma espessura material concreta. A lógica da privatização do património económico do Estado predomina, mas isso apenas se aplica a alguns sectores anteriormente nacionalizados. Basta olhar para dois indicadores para termos uma aproximação a essa materialidade do Estado. Um é a despesa pública, o outro é o peso dos serviços sociais garantidos pelo Estado. Quanto a esta última actividade, já vimos o significado que lhe atribuí e o peso que tem na criação de riqueza e no emprego (27\%, no período 2000-2003).

A despesa pública situa-se, em Portugal, em valores que equivalem a mais de $50 \%$ do PIB, como acontece na generalidade das economias semelhantes. Ela só assumiu valores relevantes (acima de 20\% do PIB) depois de 1974, quando se tratou de construir um Estado democrático 
moderno. ${ }^{14}$ Os outros patamares relevantes são os que correspondem ao processo de integração, quer na fase inicial (na segunda metade da década de oitenta, quando a despesa pública se situa à volta dos $40 \%$ do PIB), quer numa segunda fase, em que a modernização se acelera (nos anos noventa, quando este rácio ultrapassa os $50 \%$ ).

Finalmente, o contexto da União Económica e Monetária renovou e revalorizou uma clássica função do Estado, a política orçamental. Estamos, de novo, perante o papel estatal de produção de normas, consensos e opções. A questão relevante é a de saber como é que ele é exercido num contexto em que a lógica privada se torna cada vez mais forte e desafia o próprio Estado.

\section{Conclusão}

Procurei demonstrar neste texto que, entre as muitas transformações que a economia portuguesa registou depois da revolução democrática de 1974 e da adesão à CCE em 1986, ocupam lugar de relevo a integração ibérica e o papel quase exclusivo do mercado interno europeu como espaço de relacionamento económico. Considerei que isto era muito significativo para um país cujo espaço relacional era anteriormente bastante mais amplo. Referi-me às mudanças na especialização, à emergência de uma economia terciária de influência pública, à nova condição de Portugal como investidor líquido no estrangeiro e como país de imigração e à sua natureza de consumidor de poupança externa. Estes pareceram-me os indicadores mais úteis para obter um retrato actual da economia portuguesa.

Os meus argumentos mais substanciais residiram, contudo, na ideia de que, para captar o essencial do que constitui uma economia, é importante concentrar a nossa atenção nos mecanismos que coordenam a acção colectiva e colocam os actores económicos e sociais numa trajectória em que as suas atitudes e decisões convirjam. Foi por isso que me referi ao Estado, ao mercado e à comunidade. Defendi um entendimento institucionalista da economia. Estes três mecanismos são cruciais em qualquer economia, evidentemente. Por isso, tentei sublinhar a ideia de que as suas particularidades revelam as particularidades da economia portuguesa. Uma análise concreta da acção do mercado conduz-nos rapidamente aos limites e fraquezas da esfera mercantil: a sua geografia, em termos relacionais, é cada vez menor; o mercado é escassamente um agente pró-activo (na criação de uma economia de serviços auto-sustentada, por exemplo); age principalmente

\footnotetext{
${ }^{14}$ Isto não significa que não tenha sido grande a centralidade do Estado no período não-democrático. Ela não se media, porém, pela despesa pública e muito menos pelas medidas decorrentes das políticas socais.
} 
em contextos institucionalmente construídos (e até institucionalmente protegidos); ganha margens de actuação graças a contributos assegurados por outros (a disponibilidade de poupança externa ou as oportunidades de exportação criadas pela integração europeia, por exemplo). Quer dizer, o mercado (entendendo-o como o universo das acções privadas de produção, troca e financiamento), gera frequentemente défices, em vez de excedentes sociais.

Estado e comunidade são complementos necessários do mercado. A condição semiperiférica de Portugal dá à comunidade um papel importante na governação social. É assim porque, em primeiro lugar, os processos informais continuam a ser relevantes e são instrumentos de flexibilidade social e, em segundo lugar, porque as estruturas internas - território, sistemas urbanos, contextos rurais transformados, sistemas locais inovadores - interferem frequentemente nas trajectórias económicas.

A centralidade do Estado foi um dos meus mais repetidos argumentos: porque mercado e sociedade civil revelam fraquezas; porque as instituições e as acções institucionais têm uma importância crescente nos processos económicos; porque considerei a integração europeia a principal externalidade da economia portuguesa e defendi que ela foi um assunto de gestão política e pública.

Os factos estudados e as perspectivas com que procurei interpretá-los reforçaram-me a convicção de que uma economia segue frequentemente trajectórias originais e inesperadas. Por isso, é útil dispormos de instrumentos que nos municiem para refazermos o sentido que lhes cabe e percebermos o que está em causa. O contributo que aqui fica é o que consiste em encarar a governação e os mecanismos de coordenação económica de um ponto de vista amplo e não determinista, fundado em indicadores que possam ajudar a reconstruir os processos mais relevantes.

\section{Referências Bibliográficas}

Arrow, K. (1974), "Limited Knowledge - An Economic Analysis", The American Economic Review, Março, 1-10.

Delmas, Philippe (1993), O Senhor do Tempo: A modernidade da acção do Estado. Porto: ASA.

DPP - Departamento de Prospectiva e Planeamento (2003), Portugal no Espaço Europeu - O Investimento Directo Estrangeiro. Lisboa: Ministério das Finanças.

Gonçalves, O. F. (1998), "Convergência real no longo prazo da economia portuguesa", Notas Económicas - Revista da Faculdade de Economia da Universidade de Coimbra, $11,82-100$. 
Hollingsworth, J. Rogers; Boyer Robert (1997), Contemporary Capitalism: The Embeddeness of Institutions. Cambridge: Cambridge UP.

Murteira Mário (1997), Economia do mercado global: Ensaio sobre as condicionantes mega e macro das estratégias empresariais. Lisboa: Presença.

Reis, José (1993), "Portugal: A heterogeneidade de uma economia semiperiférica", in Boaventura de Sousa Santos (org.), Portugal: Um retrato singular. Porto: Afrontamento, 133-161.

Reis, José; Négrier, Emmanuel (1998), “Térritoires et régionalisation: le cas du Portugal”, in E. Négrier; Bernard Jouve (orgs.), Que gouvernent les régions d'Europe? Échanges politiques et mobilisations régionales. Paris: L'Harmattan, 161-179.

Reis, José (2000), “Industrie et dynamiques régionales: les problèmes d'une économie intermédiaire (Portugal)”, in Georges Benko; Alain Lipietz (orgs.), La richesse des régions: la nouvelle géographie socio-économique. Paris: PUF, 271-292.

Reis, José (2001a), “A globalização como metáfora da perplexidade? Os processos geo-económicos e o 'simples' funcionamento dos sistemas complexos”, in Boaventura de Sousa Santos (org.), Globalização: Fatalidade ou utopia?. Porto: Afrontamento, 109-134.

Reis, José (2001b), “Estado, instituições e economia: A despesa pública em Portugal”, in José Reis; Maria Ioannis Baganha (orgs.), A economia em curso: Contextos e mobilidades. Porto: Afrontamento, 31-61.

Reis, José (2002), “A economia portuguesa: Entre Espanha e as finanças internacionais”, Boletim de Ciências Económicas, XVL-A, 683-712.

Reis, José (2003), Economia portuguesa. Coimbra: Faculdade de Economia da Universidade de Coimbra.

Reis, José (2004), “Governação e territórios na Europa: Hipóteses sobre um subfederalismo europeu” (no prelo).

Santos, Boaventura de Sousa (org.) (2003), Portugal: Um retrato singular. Porto: Afrontamento.

Simon, H. (1986), "Behavioural Economics”, in John Eatwell et al. (orgs.), The New Palgrave - A Dictionary of Economics. London: Macmillan, 221-225. 